\title{
PENAMPILAN DAN RASA MAKANAN SEBAGAI FAKTOR SISA MAKANAN PASIEN ANAK DI RUMAH SAKIT Dr. SOBIRIN MUSI RAWAS
}

\author{
Emy Yuliantini, Emawati, Kamsiah \\ Politeknik Kesehatan Kementerian Kesehatan Bengkulu, Jurusan Gizi \\ Jl. Indragiri No.3 Padang Harapan Bengkulu \\ emyardi08@yahoo.com
}

\begin{abstract}
The purpose of this study was to determine the relationship of the patient's appearance and taste of the food with the rest of the food in the child's room inpatient hospital Dr. Sobirin Musi Rawas in 2013. This research uses a cross-sectional design with purposive sampling technique. With the independent variable ( the appearance and taste of food the patient ) and the dependent variable (food scraps ). The subjects were patients hospitalized children total sample of 40 people that match specified criteria were respondents. Analysis of the chi-square test statistic with 95\% confidence level and using SPSS. The results of the research relationship with the appearance of food waste was found that patients who expressed the food looks attractive with good leftovers as much as $60 \%$. There is no significant correlation between the appearance presented by the rest of the food $(\rho=0.191)$. The results of the research relationship with the taste of food leftovers found that patients who expressed the taste of food in accordance with the rest of the good food that is as much as 62.1 $\%$. There was a significant association between the taste of food with leftovers patients ( $\rho=$ 0.034 and $\mathrm{OR}=7.364$ value ).
\end{abstract}

Keywords : Appearances Food, Taste Food and Rest of Food

\begin{abstract}
Abstrak : Tujuan penelitian ini untuk mengetahui hubungan penampilan dan rasa makanan pasien dengan sisa makanan di ruang rawat inap anak rumah sakit Dr. Sobirin Musi Rawas tahun 2013. Jenis penelitian ini menggunakan desain Cross Sectional dengan teknik pengambilan sampel purposive sampling. Variabel independen (penampilan dan rasa makanan pasien) dan variabel dependen (sisa makanan). Subjek penelitian ini adalah pasien rawat inap anak jumlah sampel sebanyak 40 orang dan sesuai criteria yang ditentukan menjadi responden. Analisis uji statistik chisquare dengan tingkat kepercayaan 95\% dan menggunakan program SPSS. Hasil penelitian hubungan penampilan dengan sisa makanan didapatkan bahwa pasien yang menyatakan penampilan makanan menarik dengan sisa makanan baik sebanyak $60 \%$. Tidak ada hubungan yang bermakna antara penampilan yang disajikan dengan sisa makanan $(\boldsymbol{\rho}=0,191)$. Hasil penelitian hubungan rasa makanan dengan sisa makanan didapatkan bahwa pasien yang menyatakan rasa makanan sesuai dengan sisa makanan baik yaitu sebanyak $62,1 \%$. Ada hubungan yang bermakna antara rasa makanan pasien dengan sisa makanan $(\boldsymbol{\rho}=0,034$ dan nilai $\mathrm{OR}=7,364)$.
\end{abstract}

Kata kunci : Penampilan Makanan, Rasa Makanan dan Sisa Makanan

Rumah sakit merupakan salah satu sarana kesehatan yang memegang penting untuk meningkatkan derajat kesehatan masyarakat. Fungsi dari rumah sakit memberikan pelayanan yang sempurna, baik pencegahan maupun pengobatan penyakit. Keberhasilan penyelenggaraan makanan antara lain dikaitkan dengan adanya sisa makanan yang dapat menunjukkan belum optimalnya suatu penye- lenggaraan makanan di rumah sakit (Mukrie N,1990).

Penelitian Djamaludin (2002), menunjukkan rata-rata persentase sisa makanan banyak dijumpai pada waktu makan pagi berupa makanan pokok $23,1 \%$, sayur $25,35 \%$, lauk hewani $22,93 \%$ dan nabati sebesar $21,86 \%$, dan waktu makan siang sisa terbanyak pada sayur sebesar $20,33 \%$ dan lauk nabati sebesar $20,33 \%$. 
Sisa makanan yang tidak dikonsumsi oleh pasien mengakibatkan kebutuhan gizi pasien tidak adekuat, adanya biaya yang terbuang sehingga anggaran makanan jadi kurang efisiensi dan tujuan pelayanan optimal tidak tercapai (PGRS,2013).

Status gizi akan menjadi optimal bila tubuh memperoleh cukup zat gizi dan digunakan secara efisien. Asupan zat gizi yang baik bagi pasien yang dirawat inap di rumah sakit sangat diperlukan untuk membantu proses penyembuhan pasien, memperpendek lama hari rawat, mencegah timbulnya komplikasi, menurunkan mortalitas dan morbiditas yang pada akhirnya dapat menghemat biaya pengobatan (PGRS, 2013).

Hasil beberapa penelitian yang dikutip oleh Thata (2000) menunjukan bahwa 40-55\% pasien masuk rumah sakit mengalami malnutrisi berat. Rata-rata $75 \%$ penderita yang dirawat dirumah sakit status gizinya akan menurun sabanding dengan status gizi pada waktu masuk rumah sakit. Menurutnya status gizi disebabkan karena penyakit dan difesiensi zat gizi serta tidak cukupnya asupan makanan sehingga berdampak pada komplikasi. Rendahnya asupan makanan disebabkan oleh menurunnya nafsu makan sehingga makanan yang disajikan seringkali bersisa.

Berdasarkan hasil survey awal terhadap penyelenggaraan makanan pasien rawat inap di rumah sakit Dr. Sobirin Musi Rawas, dari 32 responden didapatkan sisa makanan pada tempat maka banyak bersisa pada makanan lunak diruang rawat inap anak, makanan pokok sebesar 50,2\%, Lauk nabati sebesar $23 \%$ dan sayur sebesar $26,8 \%$.

\section{BAHAN DAN CARA KERJA}

Penelitian ini menggunakan metode penelitian survey analitik melalui pendekatan potong silang. Populasi pada penelitian ini adalah semua pasien rawat inap anak Rumah Sakit Dr. Sobirin Musi Rawas. Jumlah sampel sebanyak 40 orang sesuai dengan kriteria menjadi responden. Penelitian melibatkan 2 orang enumerator yang dilatih untuk menyamakan persepsi mengenai porsi makanan, cara penimbangan makanan dan cara mengukur sisa makanan secara visual dengan meng- gunakan skala Comstock yang selanjutnya dinilai reliabilitasnya.

Penampilan dan rasa diukur dengan kuesioner dimana pasien diminta menjawab,dan cut off points ditentukan berdasarkan nilai median. Dari jumlah nilai tanggapan pasien terhadap nilai median. Dari jumlah nilai tanggapan pasien terhadap variable penampilan dan rasa menu makanan pokok dan sayuran, kemudian diklasifikasikan menjadi menarik/sesuai apabila skor nilai diatas median dan dikatakan tidak menarik/tidak sesuai apabila skor nilai dibawa median. Sisa makanan dikatagorikan bersisa jika sisa makanan banyak (> 25\%) dan dan tidak bersisa jika sisa makanan sedikit $(<=25 \%)$.

\section{HASIL}

Gambaran distribusi frekuensi Penampilan makanan pokok dan sayuran, rasa makanan pokok dan sayuran) maupun sisa Makanan. Penampilan makanan pokok dan sayur yang disajikan di Ruang Anak Rumah Sakit Dr. Sobirin Musi Rawas, Pasien menyatakan menarik sebanyak $63 \%$ dan menyatakan tidak menarik sebanyak 37\%, diperoleh distribusi frekuensi pada gambar 1 :

Gambar 1 Penampilan Makanan pokok dan sayuran

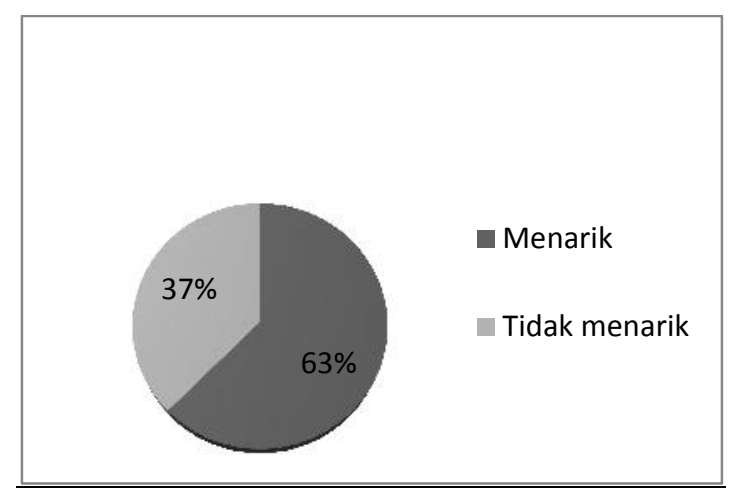

Dari 40 Pasien , sebagian besar sampel menyatakan rasa makanan pokok dan rasa sayuran yang sesuai selera pasien $72 \%$ dan tidak sesuai dengan selera pasien yaitu $28 \%$ yaitu terdapat pada bumbu dan suhu makanan yang disajikan.

Gambar 2 menunjukan bahwa sisa makanan pokok maupun sayuran sebagian besar masing-masing $50 \%$. 
Gambar 2 Rasa Makanan pokok dan sayuran

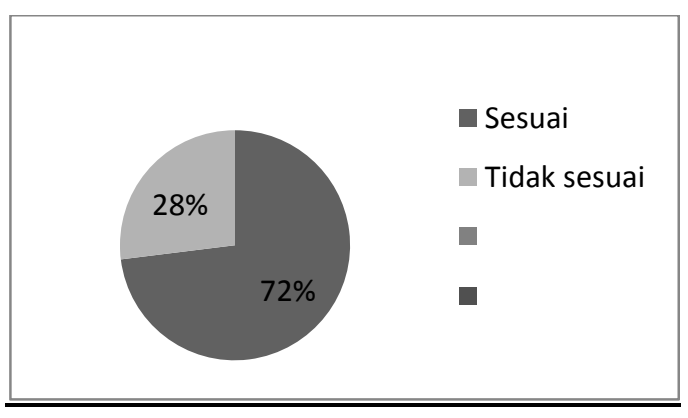

Gambar 3 Persentase sisa Makanan pokok dan sayuran

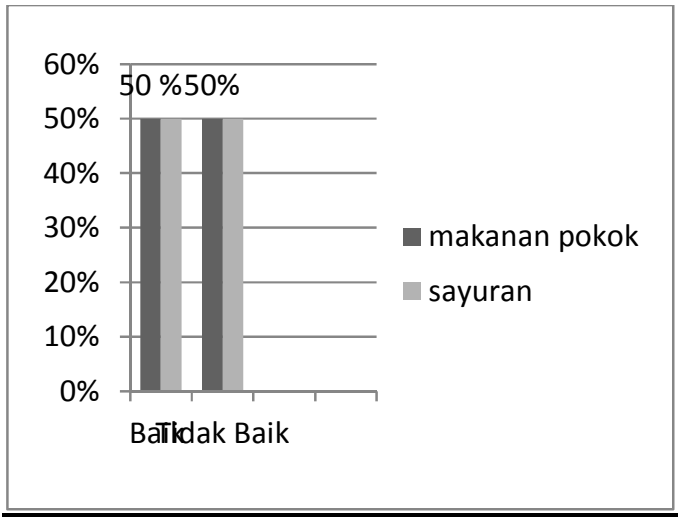

Tabel 1 Hubungan Penampilan Makanan dengan Sisa makanan

\begin{tabular}{|c|c|c|c|c|c|c|c|c|}
\hline \multirow{3}{*}{ Variabel } & \multicolumn{4}{|c|}{ Sisa Makanan } & \multicolumn{2}{|c|}{ Total } & \multirow{3}{*}{$\begin{array}{c}P \\
\text { Value }\end{array}$} & \multirow{3}{*}{$\begin{array}{c}\text { OR } \\
(\mathbf{9 5 \%} \\
\text { CI) }\end{array}$} \\
\hline & \multicolumn{2}{|c|}{$\begin{array}{l}\text { Tidak } \\
\text { Baik }\end{array}$} & \multicolumn{2}{|c|}{ Baik } & \multirow[t]{2}{*}{$\mathbf{n}$} & \multirow[t]{2}{*}{$\%$} & & \\
\hline & $\mathbf{n}$ & $\%$ & $\mathbf{n}$ & $\%$ & & & & \\
\hline \multicolumn{9}{|l|}{ Penampilan } \\
\hline \multicolumn{9}{|l|}{ Makanan } \\
\hline $\begin{array}{l}\text { Tidak } \\
\text { Menarik }\end{array}$ & 10 & 66,7 & 5 & 33,3 & 15 & 100 & 0,191 & \\
\hline Menarik & 10 & 40,0 & 15 & 60,0 & 25 & 100 & & \\
\hline \multicolumn{9}{|l|}{ Rasa } \\
\hline \multicolumn{9}{|l|}{ Makanan } \\
\hline Tidak sesuai & 9 & 81,8 & 2 & 18,2 & 11 & 100 & 0,034 & 7,364 \\
\hline Sesuai & 11 & 37,7 & 18 & 62,1 & 29 & 100 & & $\begin{array}{l}(1,3- \\
40,5) \\
\end{array}$ \\
\hline
\end{tabular}

Hasil 1 menunjukan bahwa penampilan makanan tidak menarik dengan sisa makanan tidak baik yaitu sebanyak $66,7 \%$ dan pasien yang menyatakan penampilan makanan tidak menarik dengan sisa makanan pokok baik sebanyak 33,3\%. Sedangkan dari 25 pasien, yang menyatakan penampilan makanan tidak menarik dengan sisa makanan yang tidak baik sebanyak 40,0\% dan ada pasien yang menyatakan penampilan makanan menarik dengan sisa makanan baik yaitu sebanyak $60 \%$. Dari hasil analisis didapat nilai $\mathrm{p}=0,191$. Yang berarti tidak ada hubungan yang bermakna antara penampilan makanan yang disajikan dengan sisa makanan.

Berdasarkan Tabel 1 didapatkan bahwa dari 11 pasien, yang mengatakan rasa makanan tidak sesuai dengan sisa makanan tidak baik sebanyak $81,8 \%$ dan ada pasien yang menyatakan rasa makanan tidak sesuai dengan sisa makanan baik yaitu sebanyak $18,2 \%$. Sedangkan dari 29 pasien, yang menyatakan rasa makanan sesuai dengan sisa makanan pokok tidak baik sebanyak 37,7\% dan ada pasien yang menyatakan rasa makanan sesuai dengan sisa makanan baik yaitu $62,1 \%$. Dari hasil analisis didapatkan nilai $\mathrm{p}=0,034$ yang berarti ada hubungan yang bermakna antara rasa makanan yang disajikan dengan sisa makanan. Dari hasil analisis juga diperoleh nilai $\mathrm{OR}=7,364$ artinya pasien yang berpendapat penampilan makanan tidak sesuai mempunyai peluang menyisakan makanan 7,4 kali dibanding yang berpendapat sesuai.

\section{PEMBAHASAN}

\section{Penampilan Makanan Pokok dan Sayuran}

Penampilan makanan merupakan penentu cita rasa makanan yang meliputi komponen warna makanan, konsistensi makanan, bentuk makanan, besar porsi makan dan cara penyajian makanan (Moehyi, 1992). Dari penelitian menunjukkan bahwa pasien yang menilai penampilan makanan pokok dan sayuran menarik lebih dari sebagian sebanyak $63 \%$. Hal ini karena warna, konsistensi atau kepadatan makanan, bentuk, besar porsi dan cara penyajian makanan sudah menarik dan sesuai menurut pasien. Sama halnya dengan penelitian Nurhayati dkk (2008) di RS Bhakti Wira Tamtama Semarang yaitu dari 35 pasien, hampir seluruhnya menyatakan penampilan makanan menarik.

\section{Rasa Makanan Pokok dan Sayuran}

Rasa makanan merupakan salah satu aspek utama cita rasa makanan yang terdiri dari aroma makanan, kesesuaian bumbu-bumbu, keempukan makanan, tingkat kematangan dan suhu makanan. Aspek ini sangat penting untuk diperhatikan agar dapat menghasilkan 
makanan yang memuaskan pasien (Moehyi, 1992).

Hasil penelitian sebagian sebanyak $73 \%$ pasien menyatakan rasa makanan pokok dan sayuran yang disajikan sejalan dengan hasil penelitian Munawar, 2011 di RSHS Bandung dan penelitian Nurhayati dkk (2008) di RS Bhakti Wira Tamtama Semarang yaitu dari 35 pasien, sebagian besar berpendapat rasa makanan yang disajikan enak. Rasa makanan adalah aspek penilaian yang sukar untuk dinilai secara akurat jika dibandingkan dengan tekstur dan warna makanan. Oleh karena itu, rasa makanan sangat bersifat subjektif, tergantung selera pasien yang mengonsumsinya (Brooks et al, 1966). Namun ada beberapa pasien yang menyatakan rasa makanan yang diberikan tidak memuaskan banyak menyisakan makananya baik makanan pokok maupun sayur. Makanan yang memiliki cita rasa tinggi adalah makanan yang disajikan dengan menarik menyebar bau yang sedap, dan memberikan rasa yang sedap sehingga memuaskan bagi yang memakannya, (Mehyi, 1992). Dari hasil kuesioner ternyata pasien merasa tidak sesuai dengan rasa bumbu, aroma makanan dan suhu makanan yang disajikan oleh rumah sakit tidak terlalu sedap sehingga tidak mengundang selera pasien.

\section{Sisa Makanan Pokok dan Sayuran}

Kebanyakan keluarga pasien membawa makanan dari luar atau dari rumah sehingga makanan yang diberikan rumah sakit tidak dihabiskan atau bahkan tidak dimakan sama sekali. Menurut Moehyi faktor-faktor yang mempengaruhi sisa makanan selain faktor eksternal yaitu cita rasa makanan juga adanya faktor internal yaitu nafsu makan, kebiasaan makan, rasa bosan dan adanya makanan dari luar.

Banyaknya sisa makanan pasien juga dipengaruhi oleh kebiasa dan pola makan pasien dirumah sebelum masuk rumah sakit. Karena menurut Moehyi kebiasaan makan pasien dapat mempengaruhi pasien dalam menghabiskan makanan yang disajikan. Bila kebiasaan makan pasien sesuai dengan makanan yang disajikan baik dalam hal susunan menu dan besar porsi maka pasien cen- derung dapat menghabiskan makanan yang disajikan sebaliknya bila tidak sesuai dengan kebiasaan makan pasien, maka diperlukan waktu untuk menyesuaikannya.

Penelitian yang dilakukan Sri Y tahun 2011 di RSUD propinsi Sulawasi Tenggara menunjukkan bahwa ada pengaruh penampilan dan rasa makanan pada menu yang disajikan terhadap tingkat kepuasaan pasien. Dan hal yang sama juga terdapat pada penelitian Irawati tahun 2010 Rumah Sakit jiwa Madani Palu yang menunjukkan sisa makanan terbanyak pada makanan pokok(nasi) dan sayuran kemudian baru lauk hewani dan lauk nabati.

\section{Hubungan Penampilan Makanan dengan Sisa Makanan}

Hasil analisis didapat tidak ada hubungan yang bermakna antara penampilan makanan dengan sisa makanan. Penampilan makanan sewaktu dihdangkan merupakan salah satu aspek yang menentukan penilaian seseorang terhadap cita rasa makanan. Penampilan makanan yang disajikan merangsang saraf melalui indera penglihatan sehingga mampu membangkitkan selera untuk mencicipi makanan tersebut. Penampilan makanan dalam penelitian ini meliputi warna,tekstur, bentuk dan porsi makanan tetapi pada penelitian ini karena responden adalah anak yang cenderung tidak menyukai makanan lunak dan sayuran. Jadi walaupun warna,tekstur dan porsi makanan menarik tetapi anak masih meninggalkan banyak sisa pada makanan yang disajikan.

Sementara Penelitian Puspita dan Rahayu (2011) di RSUD Dr. M. Ashari Pemalang menyatakan ada hubungan antara persepsi pasien mengenai penampilan makanan dengan terjadinya sisa makanan pasien. sebanyak 6,3 kali dibanding yang berpendapat menarik. Penelitian serupa yang dilakukan Munawar (2011) di RSHS Bandung pada pasien yang mendapat diet lunak, responden yang menilai penampilan makanan tidak menarik mempunyai peluang 39,6 kali menyisakan makanan banyak dibandingkan responden yang menilai makanan menarik. 


\section{Hubungan Rasa Makanan dengan Sisa Makanan}

Penelititan menunjukkan hubungan rasa makanan dengan sisa makanan diperoleh hubungan bermakna. Oleh karena itu, ada perbedaan proporsi sisa makanan antara pasien yang menilai rasa makanan sudah sesuai dengan yang menilai tidak sesuai. Hal ini sejalan dengan penelitian Nurhayati dkk (2008) di RS Bhakti Wira Tantama Semarang bahwa ada hubungan yang bermakna antara rasa makanan dengan sisa makanan pasien ( $p$ $<0.05$ ). Artinya, pasien yang berpendapat rasa makanan tidak sesuai akan memberikan sisa makanan yang lebih banyak, sedangkan pasien yang menyatakan makanan sesuai akan menyisakan makanan lebih sedikit. Pada tabel 4.2 diperoleh peluang pasien yang berpendapat rasa makanan tidak sesuai dengan makanan pokok dan sayuran mempunyai peluang menyisakan makanan 7,4 kali. Sesuai dengan teori Moehyi (1992) bahwa rasa makanan merupakan salah satu aspek utama yang menentukan selera makan pasien sehingga menentukan banyak atau tidaknya sisa makanan.

Rasa makanan merupakan factor yang menentukan cita rasa makanan. Rasa makanan pada penelitian ini meliputi variable aroma makanan, suhu makanan, dan tingkat kematangan. Aroma makanan akan memberikan daya tarik yang kuat yang membangkitkan selera makan. Penggunaan panas yang tinggi dalam proses pemasakan akan lebih menghasilkan aroma yang kuat dan sebaliknya makanan yang direbus, dikukus tidak mengeluarkan aroma yang merangsang. Temperatur atau suhu makanan padaa waktu disajikan memegang peranan dalam menentukan cita rasa makanan. Makanan sebaiknya dihidangkan dalam keadaan panas terutama makanan yang dapat memancarkan aroma yang sedap seperti Sop,Soto, kimlo dan lain-lain. Suhu makanan sampai kepada pasien juga dipengaruhi oleh system distribusi makanan. Hal ini sejalan dengan penelitian Sri Y (2011)

\section{DAFTAR RUJUKAN}

Bagian Gizi RS. Dr. Cipto Mangunkusumo dan Persatuan Ahli Gizi Indonesi. 2000. Penuntun bahwa aspek rasa setiap jenis makanan memiliki nilai rerata yang meningkat dengan menu pilihan.

Indicator keberhasilan mutu pelaksanaan mutu pelayanan gizi di ruang inap dapat dilihat melalui perkembangan keadaan gizi pasien dan banyaknya makanan yang disisakan. Sisa makanan dapat dinyatakan untuk mengevaluasi standar makanan rumah sakit yang ada, penyelenggaraan, dan pelayanan makanan. Namun sampai saat ini standar makanan rumah sakit belum dilaksanakan dengan optimal dalam memenuhi kualitas pelayanan makanan khususnya pasien anak.

\section{KESIMPULAN}

Mempertahankan dan meningkatkan mutu, penampilan dan cita rasa makanan yang disajikan agar tidak ada lagi makanan yang tersisa, lebih memperhatikan variasi menu terutama sayuran, melakukan peningkatan keterampilan, studi banding dan pengetahuan agar tenaga pengolah bahan makanan menghasilkan menu bervariasi dan menarik sesuai selera pasien, menyediakan menu pilihan makan pasien sesuai dengan biaya untuk mencegah kejenuhan dan menurunkan angka sisa makanan.

Bagi Ahli Gizi harus aktif melakukan penyuluhan, konseling gizi serta memotivasi makan pasien dan mengawasi pemorsian, ukuran porsi harus sesuai kebutuhan pasien dan seragam dengan cara menyediakan tempat siap cetak yang sudah sesuai dengan standar porsi. Jenis makanan dan porsi yang terlalu banyak bisa disiasati dengan cara makanan yang diganti menjadi dua kali makan. Perlu mempertahankan dan meningkatkan kualitas program pelayanan gizi menjadi semakin baik agar tujuan pelayanan gizi rumah sakit dalam rangka membantu mempercepat kesembuhan pasien dan meningkatkan derajat kesehatan masyarakat dapat tercapai secara optimal.

Diit Anak. 2000 Jakarta: PT. Gramedia pustaka Utama

Bina Diknakes. 2003. Pedoman Pelayanan Gizi Rumah Sakit. Jakarta Depkes RI. Departemen Kesehatan RI 
Departemen Kesehatan RI. 2011. Pelayanan Gizi Rumah Sakit. Jakarta. Departemen Kesehatan RI

Mukrie N, Ginting AB, Ngadiarti I, Manajemen pelayanan Gizi Institusi Dasar. Proyek pengembangan pendidikan tenaga gizi pusat dan akademi gizi Depkes RI; Jakarta; 1990

Moehji, S. 1988. Pengetahuan Makan dan Diet untuk Penyembuhan Penyakit. Jakarta. Bharata

Moehji, S. 1992 Penyelenggaraan Makanan Institusi dan Jasa Boga. Jakarta. Bharata

Moehji, S. 1999 Pengetahuan Makanan dan Diet untuk Penyembuhan Penyakit. Jakarta. Bharata.

Notonegoro, Sokidj ,2000. Metodologi penelitian Kesehatan. Jakarta. Rineka Cipta.

Almatsier, S, (2002). Prinsip Dasar Ilmu Gizi, Penerbit PT Gramedia Pustaka Baru, Jakarta.

Almatsier, S, (2005). Penuntun diet Instalasi Gizi Perjan RS. DR. Cipto Mangunkusumo dan asosiasi Diettisien Indonesia, Penerbit PT Gramedia Pustaka Baru, Jakarta.

Djamaludin, M, (2000). Analisis zat gizi dan biaya sisa makanan pada pasien di RS. Dr. Sardjito Yokyakarta, Tesis program Pascasarjana UGM, Yogyakarta.

Enjang, I, (2000). Ilmu Kesehatan Masyarakat, Penerbit PT. Citra Aditya Bakti, Bandung.

Juju Juriah, (2007). Faktor-faktor yang Mempengaruhi Sisa Makanan pada Pasien Kelas III Rawat Inap Di Rumah Sakit Umum Daerah Dr Soedarso Pontianak,Pontianak.

Jurnal Gizi Klinik Indonesia, (2008). Program Studi Gizi Kesehatan, Yogyakarta. Comstogk, E. M, Pierre, R.G., and Mackieman, Y. D, (1991).
Meansuring Individual Plate Waste In School Lunches, J. Am. Diet. Assoc, 94,290-297.

Moehyi, S, (1997). Penyelenggaraan Makanan Institusi dan Jasa boga, Bharata, Jakarta.

Moehyi, S, (1999). Pengaruh Makanan dan Diit Untuk Penyembuhan Penyakit, Gramedia, Jakarta.

Moehyi, S, (2000). Pengaruh Makanan dan Diit Untuk penyembuhan Penyakit, Gramedia, Jakarta.

Rijadi, C. (2002), Faktor-faktor yang Berhubungan denganTerjadinya Sisa Makanan Pasien Rawat Inap, Http:/www,fkm-undip.or,id

West dan wood. (1998) Food Service In Institution Sixth Education New York. Mac Milan Publising Company.

Muwarni, R, (2000). Penentuan Sisa Makanan Pasien Rawat Inap dengan Metode taksiran Visual Comstoc di RSUP Dr. Sardjito Yogyakarta, Tesis Program Pascasarjana UGM, Yogyakarta.

Comstock, E.M, Pierre, R.G., and Mackieman, Y.D., (1991). Measuring Individ

Pedoman PGRS (pelayanan gizi rumah sakit) kemenkes RI 2013

Connor P., Rozell S, (2004), Using, Visual Plate Waste to Monitor Menu Performance. J.Am. Diet Assoc.

Sabri, L, (2006), Statistika Kesehatan, PT. Raja Grafindo Persada, Jakarta.

Sri Yunanci Van Gobel, Yeni Prawiningdyah, R.Dwi Budiningsari. Menu pilihan diet nasi yang disajikan berpengaruh terhadap tingkat kepuasan pasien VIP di Rumah Sakit Umum Daerah Provinsi Sulawasi Tenggara, Jurnal Gizi Klinik Indonesia, (2011). 